\title{
Macaé: uma saudade!
}

\section{Macaé: I miss you!}

\author{
Alcina Brasileiro Hall"
}

\begin{abstract}
RESUMO
Com o objetivo de convidar professores de língua estrangeira a refletirem sobre sua prática pedagógica, este artigo incentiva a construção de conhecimento com os alunos de modo a desvelar suas identidades e promover sua transformação, tendo, por consequiência, sua atuação responsável perante a sociedade. Partindo de experiências de salas de aula de língua inglesa em uma escola municipal de Macaé, no Rio de Janeiro, na condição de professora recém-nomeada por concurso público, a autora discorre sobre suas surpresas e peripécias para atrair a atenção de alunos de um contexto social de pobreza, violência e baixa autoestima, portanto sem motivação para se tornarem sujeitos participantes de seu processo de aprendizagem. Ao longo da narrativa, a professora tece comentários apoiando-se em textos de educadores e pesquisadores como Marco Antonio Moreira e Júlio César Furtado, que discorrem sobre a aprendizagem significativa, fundamentando-se, principalmente, em leituras de Piaget, Vygotsky e Ausubel. Ao concluir que o potencial humano para o aprendizado é inesgotável e que não existe uma receita pronta, já que as escolhas metodológicas mais adequadas são altamente dependentes dos contextos onde ocorrem, a autora deixa a mensagem de que, sem comprometimento com a educação, toda prática pedagógica no ensino público brasileiro tende ao fracasso.
\end{abstract}

Palavras-Chave: Ensino de LEM; aprendizagem significativa; ensino público brasileiro

\begin{abstract}
With the objective of inviting foreign language teachers to reflect upon their pedagogical practice, this article stimulates knowledge building with students in order to unveil their identities e promote their transformation, having as a consequence their responsible behaviour towards society. Based on experiences gathered in English classrooms in a municipal school in Macaé, in Rio de Janeiro, where she had been recently appointed for a teaching position through a public entrance examination, the author discourses on her surprises and incidents to draw her students' attention to what was being taught. These students lived in a social context of poverty, violence and low self-esteem, therefore demotivated to become participants in their own learning process. Along the narrative, the teacher makes comments based on educators and researchers such as Marco Antonio Moreira and Júlio César Furtado, who write about meaningful learning and who, on their turn, are based on Piaget, Vygotsky and Ausubel. Inferring that the human potential for learning is inexhaustible and that there are no ready recipes, since the more adequate methodological choices are highly dependent on the contexts where they occur, the author leaves the message that without commitment to education, every practice in the Brazilian public education tends towards failure.
\end{abstract}

Key-Words: Teaching of foreign languages; meaningful learning; Brazilian public education

* Mestre em Letras pela UFPR, Professora de Língua Portuguesa e Inglesa (suas Literaturas e Metodologias), Professora Colaboradora dos Cursos de Capacitação do NAP do DELEM da UFPR, dos Cursos de Pedagogia e Administração da Faculdade Expoente, do Curso de Letras da Universidade Tuiuti do Paraná e dos Cursos de Pós-Graduação em Metodologia da Língua Portuguesa e Metodologia da Língua Inglesa do IBPEX-Instituto Brasileiro de Pós-Graduação e Extensão. 
Professor, a aula é mais do que seu plano de aula

Professor, não existe aula

Você faz a aula conforme ensina

E conforme você ensina

Você aprende novas lições

E quando olha para trás

Você vê lições que nunca mais voltará a ensinar. ${ }^{\dagger}$

Quando eu estava saindo de Curitiba de volta para o Rio de Janeiro em 2004, um pensamento era constante: que tipo de alunos terei em Macaé? Eu não sabia o que esperar, mas uma coisa em que acreditava era que encontraria uma excelente estrutura educacional, já que, estando localizada na Bacia de Campos, Macaé deveria ficar com boa parte da arrecadação de tributos gerados pela produção de petróleo. Eu sabia, por outro lado, que, tendo sido aprovada em segundo lugar no concurso público da prefeitura municipal para professores de inglês, eu poderia escolher a melhor escola para trabalhar. Minha ansiedade crescia.

Tudo parecia ter acontecido para o melhor. Meu sogro, um inglês que havia vivido no Brasil por cinqüenta anos, havia contraído câncer e meu marido já estava no Rio de Janeiro desde o início do ano para cuidar do pai, sendo ele filho único. Era agosto e eu já não o via há quase oito meses. Além do mais, a faculdade onde eu trabalhava teve que me dispensar, já que não havia turmas a me oferecer por conta da falta de procura pelo vestibular de inverno e porque as disciplinas de outros períodos não seriam oferecidas naquele semestre. Eu estava desempregada, embora mantivesse ainda alguns vínculos informais.

Cheguei em Macaé depois de dirigir por 14 horas, cerca de $1.200 \mathrm{~km}$, sem parar para dormir, e, ainda com minha mudança no carro, entrei no prédio onde a grande reunião para seleção das escolas estava acontecendo. Foi então que conheci a vice-diretora da E.M. de Pescadores de Macaé que me informou que sua escola fazia parte de um projeto com a Universidade Federal do Rio de Janeiro e que mantinha apenas quatro turmas, duas de $5^{\mathrm{a}} \mathrm{e}$ duas de $6^{\text {a }}$ séries, já que a escola era nova, das 7 da manhã às 5 da tarde. Durante as manhãs, explicou-me ela, os alunos tinham as disciplinas curriculares normais e, à tarde, aulas como conscientização ambiental, teatro, dança, capoeira, construção naval, técnicas de pesca e artesanato. Eu fiquei imensamente feliz ao saber que poderia fazer parte de um projeto tão

$\dagger$ Tradução livre. Em uma palestra dada durante um evento do Braz-tesol, Dr. Luke Prodromou, professor, autor e capacitador de professores pelo Conselho Britânico, disse tratar-se de uma adaptação que fez de uma canção de Juan-Manoel Serrat. 
maravilhoso, então aquela escola foi a minha primeira escolha. Eu nem queria saber onde ficava ou ouvir outras possibilidades. Estava cansada e sempre tive esse chamado para ações sociais, havendo inclusive participado de outros projetos. Era tudo o que eu queria como educadora: contribuir para que meus alunos se tornassem cidadãos críticos!

Eu esquecera de perguntar acerca da qualidade na educação pública em Macaé, mas era óbvio que, se a UFRJ estava tomando providências, nada poderia ser melhor. Eu não sabia ainda o quanto estava por me arrepender.

Eu acreditava conhecer as melhores técnicas e propostas de trabalho para o ensino de língua inglesa, havendo estudado e até ensinado os vários métodos e abordagens propostos pelos lingüistas internacionais mais eficientes. Afinal de contas, havia me tornado professora de inglês aos dezessete anos de idade, há quase trinta anos, e lidado com os mais diferentes níveis de proficiência e tipos de estudantes: crianças, jovens, adultos, graduandos, diretores de empresas e até professores de inglês. Estava ansiosa para começar, certa de que poderia fazer uma boa contribuição.

\section{UM DIA INESQUECÍVEL}

O primeiro dia foi inesquecível! Fui vaiada por quase cinco minutos por alunos de uma turma de $5^{\mathrm{a}}$ série até que o diretor aparecesse para interrompê-los e fazer sua pregação. Descobri então que eu era a quarta professora de inglês que eles haviam tido naquele ano e que, quando finalmente pareciam ter se adaptado a essa jovem professora contratada, eu apareci por lá para tomar o seu lugar. Essa não foi a única surpresa desagradável que tive naquele dia. A escola não estava estabelecida em local adequado, estando instalada temporariamente no Iate Clube da cidade. As salas de aula ficavam literalmente na praia, eram abafadas e pequenas demais. $\mathrm{O}$ vento soprava areia para cima das mesas e materiais. Algumas vezes, não havia giz disponível na escola e apenas uma vez consegui ser agraciada com cópias de texto e exercícios pelas quais tive de lutar durante dois meses. Não havia biblioteca, livro didático de inglês, acesso ao único computador da secretaria, alimentação razoável, disciplina dos alunos ou estrutura física para permanência dos professores para realização de seu trabalho, o que não é novidade em muitas escolas públicas brasileiras. Entretanto, era com essa realidade que eu tinha que trabalhar.

Macaé é uma cidade de contrastes. $\mathrm{O}$ aspecto poluído da cidade não é mostrado nos cartões postais e propagandas para turistas. À direita da praia onde se situava o Iate Clube, 
havia favelas por todo o trecho da orla, sendo onde morava a maioria dos alunos. Em 2004, Macaé foi considerada a sexta cidade do país em índice de favelização. Lá os ricos dividem o espaço com os pobres e a diferença social gritante pode ser vista em todos os lugares, especialmente nos supermercados.

\section{A FALTA DE MATERIAIS ERA O MENOR DOS PROBLEMAS}

Rapidamente aprendi que, se eu queria alcançar algum sucesso nas minhas aulas, teria que investir em criação de materiais, impressão de textos e figuras, fotocópias, aluguel de vídeos, compra de fitas para gravação, fita gomada, giz, outros objetos e, acima de tudo, de transparências porque, graças a Deus, eu havia descoberto, esquecido em uma sala de sucatas, embaixo de uma prateleira, todo empoeirado e cheio de areia, um retroprojetor no chão. Dois aparelhos de televisão e dois vídeo-cassettes também estavam disponíveis, embora precisando de conserto. Consegui usar, algumas vezes, cenas do curso da BBC "Muzzy in Gondoland", que agradaram muito.

Agora aos alunos. Eles tinham entre 10 a 16 anos de idade e se encontravam distribuídos em quatro turmas de cerca de 35 alunos cada. Sensualidade exacerbada, palavrões constantes, violência física, sujeira pelo chão e carteiras, arremesso de bolinhas de papéis e cadernos eram episódios comuns. De vez em quando, fazia-se necessária a presença do inspetor para uma repreensão mais grave ou para que fossem encaminhados por viaturas oficiais da patrulha escolar às suas residências.

Compartilharei quatro, dos muitos episódios vividos, que me ensinaram grandes lições. Um deles envolvia uma menina. Ela estava sempre dormindo durante as aulas. Era alta e tinha peso excessivo para sua idade e, por essas razões, era constantemente humilhada por seus colegas. Eu não podia tolerar tal comportamento da turma e queria que a aluna em questão ficasse acordada e prestasse atenção ao que estava sendo ensinado. Quando fui discutir o problema com o diretor, ele informou que não havia solução para o seu caso porque, depois de sair da escola, ela tinha que fazer todas as tarefas domésticas e então substituir a mãe em um bar que ficava dentro de uma zona de prostituição. A menina só voltava para casa por volta das três horas da madrugada todos os dias. Essa jovem, em seus quatorze anos de idade então, estava sempre exausta e não tinha qualquer auto-estima. Depois de dar-lhe atenção individual e dispensar-lhe afeto, ela terminou o semestre com a melhor nota da turma e nunca mais voltou a dormir durante minhas aulas. 
O segundo episódio envolveu um menino de treze anos que reagiu agressivamente me acusando de ter-lhe dado nota três em uma prova escrita. Ele amassou a folha e jogou-a em cima de minha mesa dizendo, em tom ameaçador, que sabia onde eu morava e que me faria uma visitinha com alguns de seus amigos. Eu o peguei pelo pulso antes que voltasse a se sentar e, segurando-o firmemente, disse-lhe "Em primeiro lugar, eu não lhe dei esta nota, foi você quem a tirou porque não estudou. Em segundo, eu quero que você me avise quando vai aparecer com seus amigos para que eu possa fazer um bolo de chocolate e comprar uns refrigerantes, pois os amigos dos meus alunos, assim como eles, serão sempre bem recebidos em minha casa!", ao que me respondeu "Professora, você não é mole não!", nunca mais vindo a me enfrentar.

O terceiro envolve uma menina de quinze anos que já era mãe. No final do semestre, ela me deu seu caderno de perguntas, todo decorado, pedindo-me para ser a primeira pessoa a respondê-lo. Eu me senti muito honrada com o convite e respondi ao que pude, deixando de lado as perguntas mais íntimas. Quando devolvi seu questionário, ela agradeceu e me perguntou se eu ia continuar com eles no ano seguinte. Mal sabia ela que, por aquela época, eu tencionava voltar para Curitiba e, talvez, de forma definitiva. Meu sogro já havia falecido, e meus filhos, que haviam ficado em Curitiba temporariamente sob supervisão de minha irmã, necessitavam de minha presença, pois algumas coisas haviam saído errado. Eu precisava de soluções urgentes e a mudança programada para o Rio de Janeiro com toda a família no início de 2005 teve que ser cancelada. Quando perguntei à aluna o porquê de pensar tal coisa, ela respondeu: "Porque professores como você não ficam aqui por muito tempo!" Senti um vazio existencial. Então lhe expliquei, sentindo-me meio culpada, que se, por alguma razão, eu não voltasse no ano seguinte, não seria por culpa de nenhum dos alunos ou da escola, porque eu os amava e eles mereciam o que há de melhor, mas porque meus planos de voltar definitivamente para o Rio não haviam dado certo conforme eu antecipara.

O quarto episódio foi sobre a turma de $5^{\mathrm{a}}$ série que havia me vaiado no primeiro dia de aula. A líder da turma (os líderes eram sempre as meninas), veio até mim e desculpou-se em nome da turma por seu comportamento e disse que eu não havia merecido aquele tipo de recepção. Vale aqui lembrar que eu coloquei essa turma no modo de espera. Atividades com jogos, TPR, criação de materiais divertidos, músicas, desenhos animados e filmes só eram dadas nas demais turmas. Quando os alunos começaram a me pedir tratamento igual, eu lhes disse que somente quando se comportassem e me deixassem fazer o meu trabalho. Até então, eu somente faria aquilo a que eles estavam acostumados, que era o que a professora anterior 
fazia e eles diziam gostar: copiar regras gramaticais e exercícios do quadro e receber o visto nos cadernos no final das aulas. Já em setembro, estavam recebendo as mesmas atenções.

\section{ALGUMAS LIÇÕES VALIOSAS}

Macaé foi, assim, uma grande lição para mim. Descobri que a única receita que realmente me ajudou foi a do conhecido ditado "Tell me and I'll forget, teach me and I'll remember, involve me and I'll learn”. Nada poderia ser mais verdadeiro. Então quando meus alunos estavam sentindo calor demais, eu os levava para fora e fazia algo diferente. Mas o que mais deu resultado em um desses dias de calor insuportável foi contar-lhes uma história à sombra das árvores. Eu sempre carregava comigo as figuras coloridas copiadas de um livro de leitura facilitada (reader) The Pearl, do escritor norte-americano John Steinbeck, para alguma eventualidade como essa. Cada figura continha um resumo, em inglês, sobre o que a cena representava. Claro que a história foi contada em português, mas houve muitas vantagens em trabalhar com o enredo, que é sobre um pescador de pérolas e, como eles, sobrevivia da pesca artesanal. A identificação com a história foi muito grande. Kino e sua família sofreram a usura e a indiferença das pessoas mais ricas da cidade, assim como sofriam os alunos e suas famílias. Kino, Juana e Coyotito foram caçados por ladrões e despojados do direito a residência, a trabalho justamente remunerado, a escola e, portanto, a cidadania. Os pescadores em Macaé também vinham perdendo seu direito à pesca de sobrevivência, pois foram substituídos por empresas que comandam e exploram seus recursos naturais. Muito do vocabulário da história tinha a ver com sua realidade. Palavras como "fishermen”, "boat", “sell”, "buy", "village”, "town”, "doctor", “church”, "family”, "thief”, "kill”, "shot”, “education”, já faziam parte do seu vocabulário receptivo. Temas como "o amor é mais importante que o dinheiro", "nada pode substituir a paz que a honestidade nas ações pode trazer", "a educação é a forma mais eficaz de emancipação de um povo", "violência só gera mais violência" foram levantados pelos próprios alunos e a discussão que se seguiu naturalmente à leitura foi bastante acalorada. Estratégias de pré-leitura, durante e pós-leitura foram bem recebidas, pois instigaram a curiosidade e mantiveram o nível de interesse. As meninas, especialmente, exigiam silêncio dos meninos para que eu terminasse de contar a história. Alguns alunos se sentiram tocados pelo final da história de tal forma que demonstraram raiva. Foi muito recompensador ver como eles foram bem sucedidos nas tarefas de interpretação do texto e previsão do que estava por acontecer a partir das chaves linguiísticas e com o auxílio das figuras. Paulo Freire (1983) 
estava certo ao indicar o trabalho com os "temas geradores". Ativar o conhecimento prévio dos alunos com a leitura do texto literário bem escolhido, mesmo em versões simplificadas em inglês, é um excelente caminho para a problematização de situações sócio-culturais que possam ser relacionadas à realidade e ao dia-a-dia de nossos alunos.

Conforme também nos afirma MOREIRA (2006), baseado em AUSUBEL (1978),

(...) uma das condições para ocorrência de aprendizagem significativa é que o material a ser aprendido seja relacionável (ou incorporável) à estrutura cognitiva do aprendiz, de maneira não arbitrária e não literal. Um material com essa característica é dito potencialmente significativo. [grifos do autor]

Ao retornar ao tema na aula seguinte e apresentar as estruturas das frases lidas, aprendi a nunca mais subestimar o potencial dos meus alunos para o aprendizado. Uma vez envolvidos, eles farão qualquer coisa que quisermos.

Certo dia, os alunos estavam tão agitados e entediados que eu tive que parar a aula sobre opostos no quadro e reorganizar os meus procedimentos. Lembrei de usar as técnicas da resposta física total e comecei a dar comandos em inglês. Foi tão fácil para eles compreenderem e, surpreendentemente, como participaram! Eu lhes disse bem alto "Attention!". Todos ficaram quietos. Então lhes disse em inglês que dali para frente eu seria seu sargento e que eles teriam que obedecer aos meus comandos. Comecei por ensiná-los como marchar, demonstrando em movimentos ritmados: "left, left, left, right, left". Desafiei os meninos a marcharem tão bem quanto as meninas, o que funcionou muito bem. Distribuí os

meninos e as meninas em 5 filas e saímos da sala de aula marchando, o que chamou a atenção das outras turmas e da secretaria. Foi muito engraçado ver a reação de todos. Então, começamos a praticar opostos como stop/move, up/down, fast/slow, sit/stand, loud/low, happy/sad e alive/dead. Outra lição que aprendi: ensinar pode ser muito divertido, mesmo em ambientes não favoráveis ao aprendizado, e os procedimentos do plano de aula podem ser mudados com a ajuda da intuição.

\section{CRIANDO O PRÓPRIO MATERIAL}

Para criar materiais, utilizei-me dos "Bonecos sem Lógica", que foram um grande sucesso entre os alunos. Os alunos, sem saberem que iriam trabalhar em grupos para montarem um boneco, desenharam uma das seguintes palavras: HEAD - NECK - TRUNK - RIGHT 
ARM - LEFT ARM - RIGHT LEG - LEFT LEG. Depois de terminarem, eles se reuniram no grupo da cor de seus cartões para montar seu próprio boneco. Foi uma excelente oportunidade para trabalhar as várias dificuldades de relacionamento nas turmas. Cada grupo teve que escolher o nome, idade, profissão e o maior sonho do seu boneco e apresentá-lo para a classe. Depois que todos apresentaram seus bonecos, pedi para que levantassem algumas conclusões sobre as atividades desenvolvidas. Discutimos então sobre a importância do trabalho em grupo, o prejuízo causado pela falta de comunicação e o respeito às diferenças, já que houve diferentes interpretações do que era para ser desenhado (o desenho do tronco, por exemplo, foi desenhado como tronco de árvore, e os braços e as pernas, muitas vezes, foram desenhados sem mãos e pés). Aproveitei para explorar as aparências "diferentes" dos bonecos, que, como muitos alunos, apresentam características que devem ser respeitadas no espaço escolar, pois, afinal de contas, todos têm um nome, uma história de vida e sonhos e necessitam ser acolhidos no grupo a que pertencem. Tratou-se de uma excelente oportunidade para trabalhar questões de alteridade.

Terminadas as atividades em todas as turmas, levei os bonecos para casa para copiá-los em transparência. Alguém pode estar imaginando como consegui copiar figuras quase do tamanho de uma cartolina em uma transparência A4! Passei um final de semana inteiro escaneando as figuras por partes e as cobrindo com linhas de desenho livre do word para delinear melhor os contornos (eu não tinha câmera digital). Consegui, enfim, preparar os bonecos feitos (exemplos: fig. 1 e 2 ) e foi então que utilizei o retroprojetor pela primeira vez. Surpresa geral: os alunos nunca haviam visto um retroprojetor antes e quando viram seus desenhos projetados na parede, ficaram maravilhados! Muitos vieram depois pedir para projetar os desenhos de seus cadernos e ficaram desapontados por não poderem fazê-lo, o que foi lamentável.
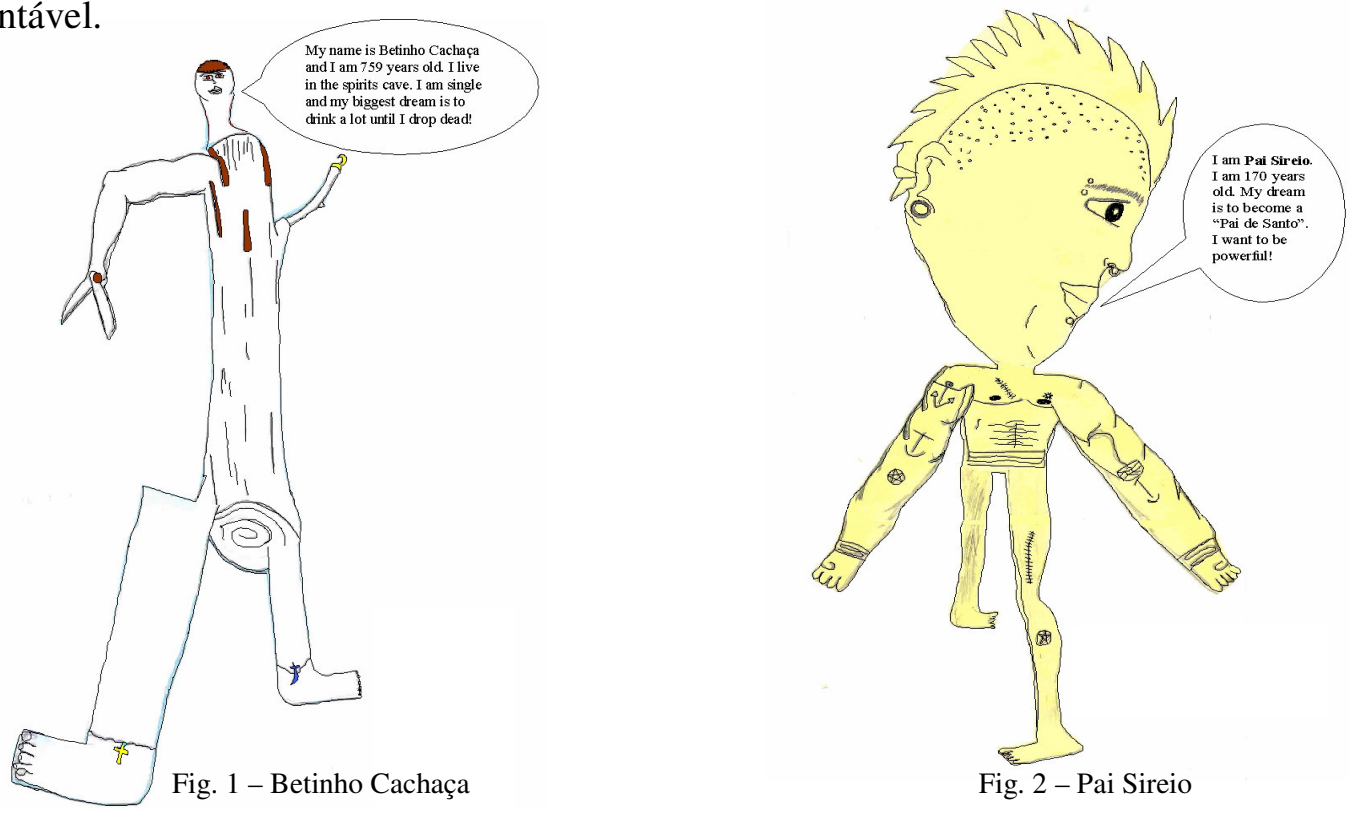
Violência, problemas de bebida, sexualidade, aspectos religiosos e outros vieram à tona nos desenhos. Tive que interferir em alguns deles, pois apesar de tê-los avisado de que desenhos inapropriados estavam proibidos, alguns alunos não se contiveram. Como consequiência, seus autores foram avisados de que seus desenhos não seriam utilizados nas atividades que se seguiriam.

Pelo fato desses bonecos terem adquirido significado para os alunos, foi muito mais fácil preparar atividades com personagens com os quais estavam envolvidos. Assim sendo, pude ensinar estruturas de forma prazerosa e mais interessante do que se tivéssemos que usar um livro didático descontextualizado (Fig. 3). Foi ótimo ver o interesse dos alunos aumentado e obter, finalmente, sua atenção para o que estava sendo ensinado. Eu havia tirado o grande prêmio!

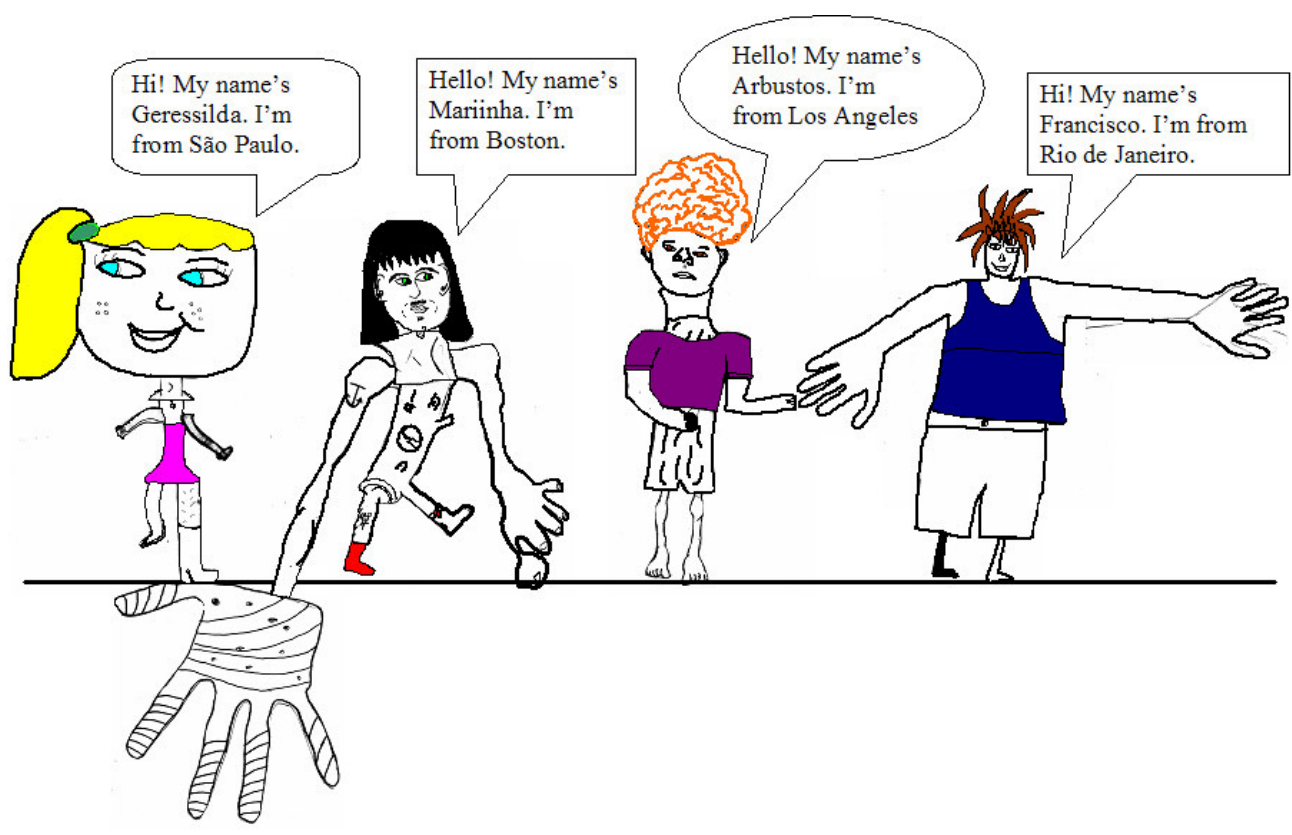

Fig. 3 - Textos preparados com os bonecos sem lógica

O que você, professor, faria se três alunas adolescentes lhe pedissem, durante o recreio, para traduzir uma música? Para quem está procurando conquistar suas turmas, você faria isso alegremente, não? Mas e se a tradução se tratasse do português para o inglês?!? E foi assim que aconteceu! Tive que traduzir a música "Você sempre será", de Marjorie Estiano, para que elas aprendessem a cantá-la em inglês. Para tal, comprei o cd Malhação Nacional (Som Livre, 2004) e me empenhei em bolar um jeito de conciliar melodia com métrica e rima. Outro final de semana debruçada sobre o computador. A tradução fez sucesso porque a música estava entre as primeiras no rádio e na televisão. Eis como ficou: 
YOU WILL ALWAYS BE / When the moon tries to find me / Tell her that I got lost / In the mist that covers the sea / But let me see you leave // Just a moment, only a look / I saw the sun rise / From behind your smile / Reminding me // That I can try to forget you / But you will always be / The wave that drags me / That takes me to your sea // I feel the calmness around me / Your wind comes to disturb / It involves me and takes me away / Drowning me again in the sea // Just a moment, only a look / I saw the sun rise / From behind your smile / Reminding me // That I can try to forget you / But you will always be / The wave that drags me / That takes me to your sea // I lose myself in your eyes / And I dive and can't realise / If I'll ever return ... // Involve me and take me / Away from here // I lose myself in your eyes / And I dive and can't realise / If I'll ever return ...

Os benefícios decorrentes dessa tradução foram enormes. As alunas cantaram a música sabendo o seu significado e, mais uma vez, as turmas sabiam muitas palavras e não lhes foi difícil fazer as associações. O ritmo lento da música também ajudou muito.

Conforme nos afirma o pedagogo, psicólogo e doutor em educação, Júlio César Furtado (2006), criador dos sete passos para a aprendizagem significativa,

a promoção da aprendizagem significativa se fundamenta num modelo dinâmico, no qual o aluno é levado em conta, com todos os seus saberes e interconexões mentais. A verdadeira aprendizagem se dá quando o aluno (re)constrói o conhecimento e forma conceitos sólidos sobre o mundo, o que vai possibilitá-lo agir e reagir diante da realidade. Cremos, com convicção e com o respaldo do mundo que nos cerca, que não há mais espaço para a repetição automática, para a falta de contextualização e para a aprendizagem que não seja significativa.

Portanto, os professores de língua inglesa não podem se considerar meros "dadores de aula", como, certa vez, ouvi uma professora se autodenominar. Precisamos levar nossos alunos a perceber o quão importantes e criativos são e o quanto podem alcançar quando trabalhando em grupos e seguindo regras básicas de boa convivência. Precisamos nos dar ao trabalho de elevar sua auto-estima e transformar o negativo em positivo, o fracasso em sucesso. Auxiliar no processo de construção de conhecimento dá trabalho, mas, para o professor que é apaixonado pelo que faz, vale a pena!

\section{A FEIRA CULTURAL}

Ao final de setembro, a coordenadora pedagógica me disse que todos os professores deveriam trabalhar o tema "Água, fonte da vida" durante a feira cultural do final do ano e que eu deveria aceitar no máximo dez alunos para apresentar as ações do Greenpeace. Apesar de 
não ter dado opção a mim e aos alunos para a escolha de um subtema, terminei aceitando a "sugestão", que era excelente. O problema é que os alunos não tinham como pesquisar sobre o assunto. Cheguei a me cadastrar no site oficial do Greenpeace e até hoje recebo seus relatórios e convocações. Apresentei aos meus alunos vários dados para discussão. Outubro foi então utilizado para trabalhos sobre aquecimento global, pesca indiscriminada, poluição de rios e mares e conscientização ambiental. Foi ótimo fazer interdisciplinaridade com o projeto da NUPEM - Núcleo de Pesquisas Ecológicas de Macaé da UFRJ. Os alunos já sabiam muitas coisas e compartilharam suas visitas ao Rio Macaé, aos manguezais e como ajudavam na limpeza das praias. Macaé possui um patrimônio ecológico fantástico: rios, praias, lagoas, restingas; até baleias aparecem encalhadas. Certa noite fiquei na orla com amigos aguardando a aproximação de cardumes de sardinhas, que brilhavam à distância sob um fantástico luar. Muitas pessoas, de tarrafas em punho, pescaram sardinhas facilmente naquela noite. Trabalhar com as disciplinas curriculares, ignorando esses fatos é um crime!

As imagens utilizadas sobre o Greenpeace foram de grande valia e são liberadas para fins educativos. Mais uma vez, os alunos me surpreenderam com a compreensão global dos textos apresentados. Em uma das transparências, havia os seguintes dizeres: "2004-10-24 International-North East Atlantic. A crew member of the Greenpeace ship MV Esperanza holds a large spider crab that has been caught and killed by an EU bottom trawler, the Playa de Menduina, fishing in Hatton Bank, NE Atlantic” (Fig. 4). É claro que tive que auxiliar com perguntas que buscavam extrair o significado das frases. As palavras em negrito já eram do conhecimento dos alunos, o resto foi de fácil conclusão. A forma americana de expressão da data, que eu ainda não havia trabalhado, acionou o interesse de alguns que perceberam a inversão da ordem que costumamos usar. Aproveitei para ensinar esse item do currículo.

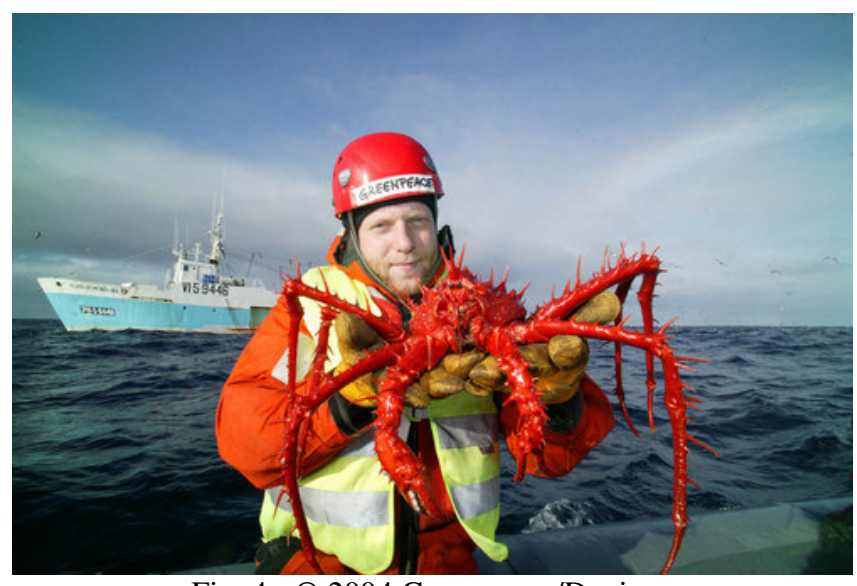

Fig. 4 - (C) 2004 Greenpeace/Davison 
Foi muito bom tratar da estrutura da língua inglesa a partir das dúvidas instauradas no diálogo com o texto autêntico. Fotos de caça a baleias, intervenções audaciosas dos ativistas, pesca excessiva e mortandade de peixes, como a que muitas vezes ocorreu na Lagoa Rodrigo de Freitas no Rio de Janeiro, foram bem exploradas. Os alunos assistiram ao vídeo do filme $O$ Dia Depois de Amanhã, lemos o texto "Segredos do Mar" e aproveitei o momento para inaugurar um concurso para as melhores redações em português. Os alunos vinham tendo muitos problemas com a escrita e o professor de português estava quase sempre ausente, renovando seus atestados médicos, em atitude de derrota perante os desafios daquela escola.

Preparei então um exercício em inglês para auxiliá-los na interpretação de uma figura em que um pescador aparece pescando um saco de dinheiro em um rio poluído, mas é atacado por um cardume de piranhas que querem o dinheiro de volta. Ao final, os alunos deveriam desenvolver um enredo, discutindo-o em grupos.

Todos quiseram participar do concurso e eu terminei tendo que ampliar o número de prêmios, de tão criativas que as redações ficaram. Os melhores textos receberam canetas, stickers, apontadores, réguas, todos muito atrativos, embora comprados em lojas de $\mathrm{R} \$ 1,99$.

Para surpresa geral, diferentemente das barracas de outras disciplinas, a de inglês contou com a participação de vinte alunos, o dobro do número máximo estipulado. Tive então que trabalhar com os alunos em dois turnos, sempre "negociando" a disciplina: quem brigasse sairia da exposição. As brigas eram muito comuns e eu mesma já havia levado um soco de raspão ao tentar desapartar uma. Era preciso zelar pelo comportamento em público.

Primeiro os visitantes assistiam às transparências utilizadas em sala de aula com as explicações de dois alunos, depois eram convidados a arriscar-se no jogo de combinar nomes com figuras de animais marinhos, jogo esse que os alunos muitas vezes fizeram em sala de aula (Fig. 5). Os alunos encarregados do jogo adoravam o fato de saberem todas as respostas e pronúncias e queriam ensiná-las aos visitantes. Duas meninas construíram duas maquetes, uma com praia limpa e outra com praia suja. Eu lhes havia dado $\mathrm{R} \$ 10,00$ para compra de materiais para que retornassem com troco e as notas, pelo que foram caprichosamente responsáveis. Um aluno distribuía o texto "Segredos do Mar", que eu havia minimizado para caber em metade de uma folha A4 para obter, com menor custo para o meu bolso, 100 cópias. Dois outros mostravam e explicavam cenas escolhidas do filme O Dia Depois de Amanhã, cujo vídeo tive que alugar novamente, levando, dessa vez, minha própria televisão e vídeo cassette. Outros dois afixavam estrelas de xerife nas roupas dos visitantes com os dizeres do 
Greenpeace "Take Action Now!". Eu as havia imprimido em número de 100 para que voluntários as levassem para casa para recortar e afixar fita dupla face no verso.

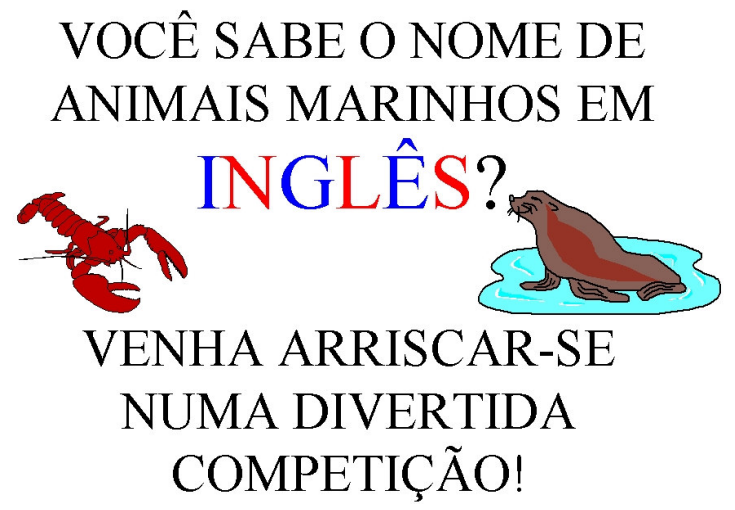

Fig. 5

O evento teve repercussão no jornal local de maior circulação. Em $O$ Debate de 18 de novembro de 2004, lê-se:

\begin{abstract}
A Escola Municipal dos Pescadores de Macaé, situada no Iate Clube, realizou ontem feira pedagógica com seus alunos, pais e toda comunidade. Com exposições de fotografias, maquetes, apresentação de dança, capoeira, dramatização, os alunos mostraram um pouco do que aprenderam ao longo do ano letivo. O fim desse projeto vem marcar o início de outro, visando enfatizar o relacionamento do homem e sua natureza. $\mathrm{O}$ evento contou ainda com a presença de Alda Corral, coordenadora da Agenda 21. O evento multidisciplinar "Água fonte da vida" envolveu assuntos como a preservação dos peixes e da água, além de deixar em evidência a necessidade do homem se sentir parte do meio ambiente e preservá-lo. Tratamento de água, movimentos ativistas como Greenpeace foram também abordados nos trabalhos apresentados.
\end{abstract}

Na continuação da reportagem, como eu já esperava, todos os créditos foram dados à administração da escola e ao projeto da NUPEM, mas pelo menos nosso trabalho foi mencionado no texto em negrito. O retorno, porém, que obtive dos alunos era mais do que eu poderia desejar. Eu teria investido tudo novamente, materiais, dinheiro, tempo, paciência e atenção, pois eles conseguiram alcançar o objetivo precípuo da educação: uma aprendizagem efetiva para a vida.

Macaé me ensinou para além das técnicas e metodologias. Eu aprendi a amar cada um de meus alunos, apesar de todo seu comportamento indisciplinado, de suas atitudes agressivas e de seus diferentes estilos de aprendizagem. Eu descobri que somente um ensino 
comprometido com a reflexão sobre o fazer pedagógico e afetividade pode funcionar nas escolas públicas inseridas em contexto de pobreza, baixa auto-estima e violência. Além de conhecer as técnicas e metodologias, precisamos usar nossa intuição e saber interpretar as necessidades e interesses de nossos alunos a fim de termos flexibilidade para uma constante adaptação. Precisaremos mudar de rumo muitas vezes, pois nada é muito estável em nossos tempos de pressão da globalização pela era do conhecimento em contraste com a mentalidade reducionista por resultados imediatos e ganância pelo poder, que levam o povo brasileiro a um distanciamento maior do acesso à educação de qualidade.

Sejamos professores apaixonados, pois, sem paixão pelo que fazemos, certamente falharemos como educadores. A melhor metodologia, portanto, será aquela que envolver nossos alunos emocionalmente, em primeiro lugar, para depois contemplar um aprendizado racional que permita, por sua vez, mudanças no proceder para o bem-estar da sociedade. Portanto, não há receitas prontas. O poeta espanhol Antonio Machado y Ruiz (1875-1939) foi muito feliz ao escrever "(...) caminante no hay camino, se hace camino al andar."

Ao considerar os educandos como passíveis de terem uma percepção mais crítica sobre suas realidades, faz-se urgente tentar desvelar suas identidades para que se tornem mais responsáveis por suas ações na sociedade.

No ano passado, a professora de religião contratada à época, que hoje afirma ter sido aquela a pior experiência de sua vida na área da educação, deu-me a triste notícia de que um dos nossos alunos havia sido morto por envolvimento com tráfico de drogas. Fiquei a imaginar se a minha presença na escola poderia ter feito alguma diferença para ele e o quanto o professor pode fazer por seus alunos. WOODWARD (2001) compartilha desse posicionamento ao comparar o professor como um jardineiro. Para ela,

(...) a good gardener is one who can create something pleasant pretty well anywhere they go, by working with what they've got. By working within limitations and building on strengths and unusual features, we can try to make a good garden anywhere. ${ }^{\S}$

Aprendi em Macaé, em um período de apenas quatro meses, que nós, professores de língua estrangeira, podemos salvar nossos jardins da indiferença política e da administração

¥ “(...) wanderer, there is no road, / the road is made by walking.” (CRAIGE, 1978).

$\S$ Trad. Livre: Um bom jardineiro é alguém que pode criar algo prazeroso muito bem aonde quer que vá, trabalhando com aquilo que tem. Trabalhando dentro de limitações e construindo a partir de pontos fortes e características incomuns, podemos tentar fazer bons jardins em qualquer lugar. 
descomprometida, mostrando aos nossos alunos o quanto eles são importantes e o quanto podem alcançar para que não percam as esperanças. O que será do jovem sem esperança? $\mathrm{O}$ que será do amanhã sem jovens comprometidos com o conhecimento?

De volta em Curitiba, custei a me readaptar, pois, em cada rosto de estudante que via nas ruas, identificava traços de meus alunos de Macaé, o que me levou muitas vezes a chorar. Diferentemente de muitos professores que conheci, para mim eles sempre serão o tipo de alunos que deixarão saudades, aonde quer que eu vá.

\section{Referências}

AUGUSTO, Alexandre. Escola Municipal de Pescadores de Macaé realiza fechamento de projeto pedagógico. O Debate, Diário de Macaé. 18 nov, 2004.

CRAIGE, Jean. Selected poems of Antonio Machado. University of Georgia, 1978. Disponível em http://www.cha.uga.edu/bjc/machado.htm Acesso em Set, 2007.

FREIRE, Paulo. A importância do ato de ler. São Paulo: Cortez, 1983.

FURTADO, Júlio César. A aprendizagem significativa passa pela avaliação formativa. Disponível em http://www.juliofurtado.com.br/artigos.html Acesso em Ago, 2007.

GREENPEACE. Image gallery. Disponível em http://www.greenpeace.gen.nz/gallery/ 2004/o2410042 Acesso em Out, 2007.

MOREIRA, Marco Antonio. A teoria da aprendizagem significativa e sua implementação em sala de aula. Brasília: UNB, 2006.

WOODWARD, Tessa. Planning lessons and courses: designing sequences of work for the language classroom. Cambridge, UK: CUP, 2001. 